\title{
Panorama de la educación literaria en las aulas universitarias
}

Overview of literary education in university classrooms

\begin{tabular}{l} 
Indira Gómez-Arteta \\
0000-0001-6489-2261 \\
\hline
\end{tabular}

Universidad Nacional del Altiplano, Puno, Per

igomez@unap.edu.pe
Recibido: 09/08/2020

Aceptado: 26/11/2020

Pub7icado: 17/03/2021

\section{Resumen}

La formación integral de estudiantes universitarios comprende, entre otras, el desarrollo de competencias blandas, que han descuidado para darle mayor interés a las competencias específicas y de especialidad. Una de las competencias blandas es la competencia literaria, que engloba las habilidades de comprensión y producción de textos. Bajo esta premisa se realizó una investigación descriptiva, con el propósito de identificar el panorama de la educación literaria en la Universidad Nacional del Altiplano, considerando como dimensiones de análisis: identificación de asignaturas que abordan la educación literaria, modelo asumido en el uso de la literatura, estrategias de enseñanzaaprendizaje y nivel de comprensión y producción de textos de los estudiantes. Para recoger datos se utilizaron 3 técnicas: análisis documental, encuesta y examen. Los resultados muestran que el $77 \%$ de las Escuelas Profesionales tienen asignaturas que desarrollan la competencia literaria, abordada desde dos modelos: el modelo textual y el modelo basado en el conocimiento del texto; las estrategias más usadas son: escritura creativa, dramatización, comentario de textos y elaboración de ensayos; el nivel de comprensión y producción de textos es medio. Se concluye que la educación literaria es parte del currículo universitario, implícita o explícitamente, promoviendo el desarrollo de varias competencias blandas.

Palabras clave: Educación literaria, modelo, estrategias, comprensión de textos, producción de textos.

\begin{abstract}
The integral training of university students includes, among others, the development of soft skills, which have been neglected to give greater interest to specific and specialty skills. One of the soft skills is communicative competence, which encompasses the skills of understanding and producing texts. Under this premise a descriptive research was carried out, with the purpose of identifying the panorama of literary education at the National University of the Altiplano, considering as dimensions of analysis: identification of subjects that address literary education, model assumed in the use of literature, teaching-learning strategies, and students' level of comprehension and production of texts. Three techniques were used to collect data: document analysis, survey and examination. The results show that $77 \%$ of Professional Schools have subjects that develop literary competence, approached from two models: the textual model and the model based on the knowledge of the text; the most used strategies are creative writing, dramatization, text commentary and essay writing; the level of comprehension and production of texts is average. It is concluded that literary education is part of the university curriculum, implicitly or explicitly, promoting the development of various soft skills.
\end{abstract}

Keywords: Literary education, model, strategies, text comprehension, text production. 


\section{Introducción}

En las últimas décadas la educación superior se ha enfrentado a varios problemas, siendo uno de ellos el retroceso en materia de formación humanística. La formación integral se ha empobrecido por las exigencias del mercado, más formales y menos humanas (Blázquez y Martínez-Lozano, 2012). Así, "la enseñanza de las ciencias, las artes y las profesiones ha ido cayendo en una mecanización, perdiendo su núcleo humanístico y su dimensión espiritual" (Hoevel, 2015, p. 49). Esta situación ha generado que se descuide el tratamiento de competencias morales, sociales y ciudadanas, que tendrá como efecto la formación de profesionales egoístas yconmínimaconcienciaderesponsabilidad social (Licandro y Yepes, 2018). Frente a ello, la Universidad ha comenzado a diseñar planes de estudio basados en la definición de competencias (Clavijo, 2015). Así, la Universidad Nacional del Altiplano (UNA), desde el año 2013 asume un modelo educativo sociocrítico-cognitivo, orientado a la formación de profesionales competentes (PEU, 2013). Este enfoque busca la formación integral de los estudiantes universitarios, la cual, según Tobón (2010) se refiere al desarrollo que implica la totalidad del ser humano: dimensión física, espiritual, social y mental. El enfoque basado en competencias, está orientado al desarrollo de capacidades por medio del logro de un perfil profesional diverso y complejo, relacionado indesligablemente al entorno de trabajo y al espacio social (Martínez, 2009). Para ello se propone el desarrollo de competencias genéricas y especializadas. Las competencias genéricas involucran procesos que nunca concluyen, ya que siempre se pueden mejorar y seguir desarrollándolas a lo largo de la vida (Díaz, 2006). $\mathrm{Al}$ respecto, uno de los rasgos de las competencias del perfil del egresado de la UNA Puno se refiere a la capacidad de comunicación oral y escrita, ligada directamente al conjunto de componentes curriculares que deben desarrollar el aspecto de comunicación y aprendizaje, como parte de los estudios generales (PEU, 2013). Estos últimos rasgos llevan a abordar el tema de la competencia comunicativa, considerada como un conocimiento que posibilita la comprensión y producción de textos (Aguiar, 1980). Esta competencia se torna imprescindible, llevando a afirmar que:

Los paradigmas pedagógicos más efectivos en la formación de las nuevas generaciones son aquellos que se conciben en y desde la comunicación, porque no es posible la formación de seres humanos íntegros al margen de la comunicación en el universo dialógico del lenguaje (Vargas, 2009, p. 34).

La competencia comunicativa se configura a través del desarrollo de otras competencias, tales como la lingüística, paralingüística, pragmática, textual y literaria. Esta última es motivo de análisis en el presente estudio, ya que se considera que ella es fuente de desarrollo de varias capacidades imprescindibles para la formación integral del estudiante universitario, proporcionando información social, filosófica, estética, lógica y cultural, entre otras. Así, por ejemplo, según Rabuzzi (1982), las novelas permiten conocer situaciones que difícilmente se encuentran en libros de texto tradicionales de medicina. Por su parte, Baños (2003) afirma que incluir un curso sobre literatura puede ayudar a que los estudiantes obtengan un bagaje de conocimientos y actitudes útiles para ejercer mejor su profesión. Por ello, es necesario conocer cómo se está trabajando en las aulas universitarias, para fomentar o fortalecer su desarrollo.

El concepto de competencia literaria se introduce en la enseñanza de la literatura ya a finales de los años sesenta. Supone un cambio de orientación y de objetivos muy importante ya que los alumnos dejarán de ser considerados, prioritariamente, como receptores de un legado histórico que les convierte en miembros de una comunidad (Colomer, 2002, p. 12).

La competencia literaria se concibe como un proceso de desarrollo de capacidades y destrezas alcanzadas por el alumno resultado de la articulación entre sus conocimientos literarios, saberes interculturales, habilidades expresivas $\mathrm{y}$ comprensivas, hábitos $\mathrm{y}$ actitudes del dominio cognitivo, lingüístico y emocional a través del contacto directo y del disfrute de la obra literaria para poder establecer valoraciones y asociaciones en el orden de lo literario (Tiza, Campos y Castellón, 2016, p. 120).

La competencia literaria se concibe como un elemento de la competencia comunicativa que contiene las capacidades de lectura, comprensión, interpretación y valoración de diversos textos literarios; permitiendo gozar mientras se lee o 
escucha el texto, desarrollando la imaginación y la capacidad de producir textos literarios orales y escritos (Prado, 2004).

Utilizar la literatura para desarrollar competencias genéricas en estudiantes universitarios es una herramienta entretenida y fructífera; ya que, trabajada de manera pertinente, ayuda a acercarnos a la consecución de los cuatro pilares fundamentales de la educación: aprender a conocer, aprender a hacer, aprender a vivir juntos y aprender a ser (Delors, 1996), permitiendo la formación integral del ser humano. Por ello, es importante destacar la importancia de relacionar la competencia literaria con un modelo didáctico adecuado para trabajarla en las aulas, el cual permita utilizar estrategias dinámicas para desarrollar habilidades de lectura, escritura, expresión y creación oral (Prado, 2004).

Con ese propósito, es importante analizar cómo se debe trabajar la literatura en las aulas universitarias; no sin antes revisar los modelos didácticos que han transitado a través de los años para el abordaje de la literatura, que según Prado (2004) son los siguientes:

1) Modelo retórico, que corresponde a la edad media. Se usa el texto clásico como modelo ético y discursivo para decir y redactar.

2) Modelo historicista, que se extiende hasta la década de los 70. El propósito de trabajar literatura es conocer los movimientos literarios, autores y principales obras, según la historia de la literatura, siendo un modelo relativamente sencillo pues los contenidos se organizan considerando ejes históricos.

3) Modelo textual. Usa el comentario de textos como refuerzo para mejorar la comprensión de lectura, siendo una actividad complementaria al historicismo literario.

4) Modelo basado en el conocimiento del texto. Desde 1980 hasta nuestros días. Prioriza los procesos de comprensión y elaboración del pensamiento e intertextualidad. Se basa en los principios de la psicología cognitiva. Busca la comprensión, interpretación y creación literaria, motivando el interés por la lectura. En este modelo no se habla de didáctica de la literatura sino de una educación literaria, propiamente dicha.
Se puede deducir, que en un enfoque educativo basado en competencias, la mejor manera de abordar la literatura es a través del modelo basado en el conocimiento del texto, es decir se debe optar por una educación literaria, la cual es mucho más compleja que la "enseñanza", porque "la literatura no se enseña ni se adquiere, sino que se aprehende" (Luengo, 1996, p. 15).

El espacio para la educación literaria debe ser, ante todo, un espacio de imaginación y creatividad que permita el desarrollo de la sensibilidad estética para la comprensión de los textos literarios, la escritura creativa de intención literaria, y el estudio crítico y reflexivo de las obras literarias (Vargas, 2009, p. 39).

Estudios anteriores demuestran que "la literatura, como uno de los espacios vitales de comunicación humana, se constituye en una de las artes más trascendentales de la vida cotidiana y la vida estética del hombre" (Vargas, 2009, p. 37). Además, "en una época marcada por la globalización, la fragmentación y la crisis de determinados pilares procedentes de siglos anteriores, la literatura proporciona al ser humano el mayor proyecto cognoscitivo con el que este puede soñar: el conocimiento de sí mismo" (Ibarra y Ballester, 2016, p. 307), pudiendo cumplir múltiples funciones: comunicativa, significativa, cognoscitiva, ética y otras (Vargas, 2009), dándole énfasis a las funciones estéticas y educativas con carácter formativo (Kusá, Sladováb y Kopecký, 2014). Así mismo, la educación literaria no solo está relacionada con la función informativa, formativa y estética, sino que, gracias a su conexión con otras materias de carácter formativo, se relaciona con la educación ética, personal y social (Kusá et al, 2014). Así, se puede hablar, incluso, de una educación literaria multicultural, que se concibe como un área educativa basada en la función formativa y de enculturación, común a ambas disciplinas. (Kusá, Sladová, Kopecký y Mlčoch, 2014).

Además, "la educación literaria debe realizarse a través de acciones comunicativas dialógicas: escenificación, lectura y escritura" (Vargas, 2009, p. 39), considerando que busca que el estudiante entienda la literatura como el reflejo de una determinada realidad y a través de ella 
desarrolle un conocimiento personal y social (Mata y Villarrubia, 2011). Estas ideas nos llevan a afirmar que una verdadera educación literaria en las aulas universitarias orienta al desarrollo de varias competencias genéricas, consideradas en la propuesta del "Proyecto Tuning América Latina", pues ayuda a potenciar la comunicación oral y escrita, la capacidad crítica y autocrítica, las habilidades interpersonales, apreciación de la diversidad y multiculturalidad, compromiso ético y ciudadano, entre otras; considerando que:

El conocimiento que el texto literario proporciona trasciende los límites de la aprehensión de conceptos o la mera proximidad respecto de determinadas conductas, porque precisamente a partir de la vivencia de infinitas posibilidades y caracteres proporciona a su receptor una interpretación del cosmos (Ibarra y Ballester, 2016, p. 306).

En este sentido, es importante hacer referencia a las distintas actividades y estrategias que ayudan a desarrollar la educación literaria, brindando a los estudiantes espacios de reflexión, entretenimiento, creación y disfrute del texto.

La lectura y escritura de textos literarios son el eje de las acciones orientadas a usar y disfrutar de la comunicación literaria. Para ello, existen diferentes actividades que se pueden realizar en el proceso de enseñanza; así, la lecturay dramatización se orientan a generar la experimentación en el intercambio comunicativo, formar la autoimagen del estudiante y desarrollar su conciencia de identidad cultural. Al respecto, Tejerina (1994) define la dramatización como una práctica organizada que "usa el lenguaje dramático con la finalidad de estimular la creación y como medio educativo para favorecer el pleno desarrollo de la persona" (p. 8), ayudando a los estudiantes en la construcción de su propia realidad desde una visión personal (González, 2015). Por otro lado, actividades como debatir, realizar ejercicios comprensivos y expresivos sobre los textos leídos y especificar algunas pautas para analizar obras literarias son ayudas para que los estudiantes avancen hacia el logro de un aprendizaje interpretativo. También, acciones como la sistematización analítica de los elementos textuales o los ejercicios de recursos estilísticos generan espacios de práctica y reflexión útiles para los aspectos anteriores (Colomer, 2010). Adicionalmente, otras estrategias concretas son las siguientes: el comentario de textos, que se orienta a interrelacionar el fondo y la forma para descubrir la intención del autor (Lázaro y Correa, 1970); la escritura creativa, que según Morote (2014) posibilita el juego imaginativo para crear, recrear o manifestar con palabras o imágenes lo fundamental de un discurso, agregando Dueñas (2013) que es una tradición lúdica e intelectual; la elaboración de ensayos es otra actividad muy útil, considerando que el ensayo es un tipo de texto argumentativo que se redacta en prosa, con el propósito de defender una postura o tesis y convencer a los receptores de la pertinencia de la misma (Zambrano, 2012).

Con las consideraciones anteriores, se ha planteado como objetivo general describir el panorama de la educación literaria en las aulas de la Universidad Nacional del Altiplano de Puno Perú, identificando las asignaturas que promueven una educación literaria, el modelo asumido en el uso de la literatura, las estrategias utilizadas y el nivel de comprensión y producción de textos de los estudiantes.

\section{Metodología}

Se ha propuesto una metodología de investigación cuantitativa, con un alcance descriptivo, ya que "busca especificar propiedades y características importantes de cualquier fenómeno que se analice" (Hernández, Fernández y Baptista, 2014, p. 92). Corresponde al diseño no experimental transeccional, cuyo propósito es "describir variables y analizar su incidencia e interrelación en un momento dado" (Ibídem, p. 154).

La población accesible la han conformado los estudiantes de la Universidad Nacional del Altiplano de Puno, durante el semestre académico 2019-I. Se seleccionó una muestra no probabilística intencional o por conveniencia, considerando las características de la investigación y los propósitos de la investigadora (Hernández, Fernández, \& y Baptista, 2014). Esta selección respondió al siguiente criterio: estudiantes que estén cursando los dos primeros ciclos durante el semestre 2019-I, ya que en estos ciclos se aborda con énfasis la competencia comunicativa, a través de componentes curriculares como Comprensión de Textos y Producción de Textos, los cuales ayudan a desarrollar el aspecto de comunicación y aprendizaje, como un elemento de la formación general de los estudiantes. El total de la muestra seleccionada ascendió a 1225 estudiantes, 
considerando a un solo grupo, por ciclo, en cada una de las 35 escuelas profesionales de la UNA.

Para la recolección de datos, se utilizaron como técnicas: la encuesta, el análisis documental y el examen. Los instrumentos fueron: el cuestionario, la ficha de análisis documental y la prueba escrita. Estos fueron analizados y revisados por un grupo de expertos en el área, asegurando su validez de contenido y constructo. La descripción de estos instrumentos se detalla a continuación:

El cuestionario constó de 18 preguntas y se dividió en dos partes: la primera se orientó a descubrir el modelo asumido en el uso de la literatura, considerando 10 preguntas mixtas, 4 de ellas se referían al propósito y 6 , a las habilidades que desarrollan al usar textos literarios; la segunda parte buscó identificar las estrategias más usadas en la educación literaria que se desarrolla en las aulas universitarias y conocer la utilidad de esta en la vida de los estudiantes, considerando 8 preguntas: 3 de alternativa múltiple y 5 mixtas. Este cuestionario se aplicó a todos los estudiantes que conformaron la muestra.

La ficha de análisis documental se usó para revisar los planes de estudio de cada Escuela Profesional y los sílabos de los dos componentes curriculares mencionados en acápites anteriores, con el propósito de identificar en cuántas Escuelas trabajan estos componentes, así como para saber cómo abordan la educación literaria desde el proceso de planificación curricular.

La prueba escrita midió la comprensión y producción de textos. La primera parte consideró 10 preguntas de comprensión de textos, combinando 5 preguntas de alterativa múltiple y 5 preguntas abiertas, las cuales se derivaron de un texto literario único para todas las escuelas profesionales. La calificación de estas preguntas se realizó con una escala vigesimal, considerando 0 o 2 puntos para cada pregunta de alternativa múltiple y una categorización de 0,1 o 2 puntos para las preguntas abiertas, en base a una escala de calificación. La segunda parte midió la producción de textos escritos, considerando 5 preguntas abiertas, las cuales se calificaron con una escala vigesimal, considerando una categorización de 0 a 4 puntos por cada pregunta, en base a una escala de calificación con especificaciones concretas. Los puntajes obtenidos, permitieron establecer tres niveles: bajo (0-10), medio (11-15) y alto (16-20).
Esta prueba se aplicó durante 1 hora en diferentes momentos a cada Escuela Profesional.

Los datos se analizaron usando, mayoritariamente, la distribución de frecuencias, que permitió organizar los datos cuantitativos. Así mismo, se utilizó el procedimiento de categorización de información para analizar las preguntas abiertas del cuestionario.

\section{Resultados y discusión}

El primer resultado (tabla 1) muestra que en el $77 \%$ de las Escuelas Profesionales se desarrollan componentes curriculares de comprensión de textos y/o producción de textos; especificando que en 12 Escuelas se trabajan los dos componentes curriculares en semestres distintos; en 9 Escuelas, solo se trabaja comprensión de textos; en 2 Escuelas, solo se trabaja producción de textos; y en 5 , se fusionan ambos en un componente curricular. Esta información permite deducir que los planes de estudio de estas Escuelas fomentan el desarrollo de competencias genéricas, específicamente de la competencia comunicativa. Por otro lado, existen 8 Escuelas Profesionales (23\%) que no consideran en sus planes de estudio ningún componente que fomente la educación literaria.

Tabla 1.

Componentes curriculares que abordan la educación literaria

\begin{tabular}{|c|c|c|}
\hline \multirow[t]{2}{*}{ Componentes Curriculares } & \multicolumn{2}{|c|}{$\begin{array}{c}\text { Escuelas } \\
\text { Profesionales }\end{array}$} \\
\hline & fi & $\%$ \\
\hline $\begin{array}{l}\text { Comprensión de textos y producción de } \\
\text { textos, por separado. }\end{array}$ & 12 & 34 \\
\hline Solo Comprensión de textos & 9 & 26 \\
\hline Solo Producción de textos & 2 & 6 \\
\hline $\begin{array}{l}\text { Comprensión y Producción de Textos, en } \\
\text { un solo curso }\end{array}$ & 4 & 11 \\
\hline No abordan ninguno de los componentes & 8 & 23 \\
\hline Total & 35 & 100 \\
\hline
\end{tabular}

Así mismo, llama la atención que de las 27 Escuelas Profesionales en las cuales se trabajan estos componentes, 20 de ellas han orientado la denominación solo al aspecto académico, dejando poco espacio para el trabajo de lo literario; así, por ejemplo, un componente se denomina: "Comprensión de Textos Académicos". Sin embargo, en la práctica, según lo expresado por los estudiantes encuestados y luego de la revisión de los sílabos correspondientes, se reconoce que los docentes utilizan la literatura como base para llegar a otros tipos de texto, fomentando que el estudiante lea, analice, comente, critique y produzca textos 
literarios, ya que estos les proporcionan las herramientas básicas para desarrollar aspectos cognitivos, éticos y fundamentalmente estéticos. Esta información nos muestra que los docentes encargados de estos componentes curriculares reconocen la importancia de la literatura en el desarrollo de habilidades comunicativas y se esfuerzan en trabajarlas, aun cuando el sistema quiera opacarlas. Esto implica que la literatura es parte del currículo oculto en la mayoría de planes de estudio.

Afirmar que los planes de estudio del $77 \%$ de las Escuelas Profesionales de la Universidad Nacional del Altiplano fomentan el desarrollo de competencias genéricas es un aspecto muy positivo, pues se enmarca en un enfoque por competencias, cuyo fin es el desarrollo integral del ser humano, que "no se refiere a la activación de habilidades y a la formación de hábitos para lograr la excelencia, sino a ese desarrollo que involucra la totalidad del ser humano: lo físico, lo espiritual, lo social y lo mental" (Tobón, 2010, p. 30). Con ello se demuestra que los currículos de la Universidad Nacional del Altiplano de Puno se están orientando a la búsqueda de la formación integral de sus estudiantes, considerando que "los requerimientos internacionales han exigido a las instituciones educativas redireccionar sus metas" (Barrales, Villalobos, Landín, Pérez, Cruz y Rodríguez, 2012, p. 38). Sin embargo, la forma en que se trabajan algunas competencias genéricas, resulta ser insuficiente, ya sea por el número de componentes curriculares, por las horas dedicadas a ellos o las estrategias que se utilizan; es poco lo que se puede hacer, ya que las acciones no tienen continuidad. Esta situación sustenta la idea de concebir que las competencias genéricas incluyen:

Procesos que nunca concluyen, pues siempre se puede mejorar la competencia ciudadana o para la tolerancia; de igual manera la habilidad lectora se encuentra en un proceso incremental cualitativo no sólo a lo largo de la escolarización, en el caso de que el sujeto concluya con estudios superiores e incluso de posgrado, sino a lo largo de su vida" (Díaz, 2006, p. 22)

Esto nos lleva a pensar en la necesidad de desarrollar las competencias genéricas a lo largo de toda la formación profesional y, de manera autónoma, después de ella.
Por otro lado, es necesario analizar el hecho de que los componentes curriculares de comprensión y producción de textos se hayan orientado, en su mayoría, solo al abordaje de textos académicos, mermando la importancia de los textos literarios. Esta situación confirmaría la idea de sostener que "la enseñanza de las ciencias, las artes y las profesiones ha ido cayendo en una mecanización, perdiendo su núcleo humanístico y su dimensión espiritual" (Hoevel, 2015, p. 49), además de descuidarse "el desarrollo de competencias morales, sociales y de conciencia ciudadana [...], lo cual limita las posibilidad de contar en el futuro con líderes comprometidos con un desarrollo inclusivo y sostenible" (Licandro y Yepes, 2018, p. 14). Esta realidad hace que se desaproveche una maravillosa oportunidad de desarrollar varias competencias genéricas; ya que, los textos literarios permiten desarrollar capacidades comunicativas, cognitivas, afectivas, personales, interpersonales, éticas y estéticas imprescindibles para el desenvolvimiento de todo profesional, reafirmando que "en una época marcada por la globalización, la fragmentación y la crisis de determinados pilares procedentes de siglos anteriores, la literatura proporciona al ser humano el mayor proyecto cognoscitivo con el que este puede soñar: el conocimiento de sí mismo" (Ibarra y Ballester, 2016, p. 307). Esta última idea, está implícita en el actuar de los docentes encargados de trabajar componentes curriculares de comprensión y producción de textos y por ello han optado por promover la lectura y escritura de textos literarios, antes de analizar los académicos. Este resultado fáctico refuerza la idea de Mata y Villarrubia (2011) quienes proponen que la educación literaria aspira a que el estudiante sepa que la literatura es el reflejo de un momento histórico, tiene vínculos con otras manifestaciones artísticas, recrea temas para analizar, es un medio de conocimiento personal y social, manifiesta el lenguaje con su gran variedad de recursos estilísticos y expresivos, está presente en diversos tipos de texto, formando parte de los procesos de producción y transmisión social. Por ello, se ratifica que la educación literaria se basa en la función formativa y socializadora del proceso literario-educativo (Kusá et al, 2014).

El segundo resultado muestra la delimitación de cuál es el modelo que se utiliza para trabajar la literatura en las aulas universitarias, implícita o explícitamente (Tabla 2). 
Tabla 2.

Modelos que se utilizan para abordar la literatura.

\begin{tabular}{lcc}
\hline Modelos & \multicolumn{2}{c}{ Escuelas } \\
& \multicolumn{2}{c}{ Profesionales } \\
& fi & \% \\
\hline Modelo retórico & 0 & 0 \\
Modelo historicista & 0 & 0 \\
Modelo textual & 6 & 22 \\
Modelos basados en el conocimiento del & 21 & 78 \\
texto: educación literaria & 27 & 100 \\
Total & & \\
\hline
\end{tabular}

Considerando únicamente a las 27 Escuelas Profesionales que consideran en sus planes de estudio componentes curriculares de comprensión y/o producción de textos, se sabe que coexisten dos modelos, de acuerdo a la propuesta de Prado (2004): el modelo textual, orientado a que el estudiante utilice el comentario de textos para mejorar su comprensión lectora; y el modelo basado en el conocimiento del texto, que específicamente corresponde a la educación literaria, centrando su atención en los procesos de comprensión y construcción del pensamiento e intertextualidad, buscando la interpretación y la creatividad literaria. Este último modelo es el que más se utiliza. Los estudiantes universitarios usan los textos literarios para despertar y hacer crecer su sensibilidad e identificación con la problemática actual, pues afirman que lo que pretenden hacer al leer textos literarios es ampliar sus conocimientos, ya que la literatura trae cultura y una visión totalizadora de los hechos de manera mágica, que les permite deleitarse con su análisis, desarrollar su sentido crítico y, motivados por sus docentes, no solo leen y comentan por obligación; sino, en la mayoría de los casos construyen críticas, desarrollan su aspecto ético y construyen su ciudadanía; aunque, ellos destacan que disfrutan estas actividades siempre y cuando el texto sea corto; lo cual muestra una debilidad que también se presenta en todo el sistema educativo peruano: la falta de un hábito lector. Al respecto, es alentador haber encontrado que prima el modelo basado en el conocimiento del texto, que específicamente corresponde a la educación literaria. Este modelo, según Prado (2004) centra su interés en la comprensión y elaboración del pensamiento e intertextualidad, tratando de conseguir el desarrollo de habilidades literarias interpretativas y creativas. Esta afirmación tiene sentido al concebir que "la literatura no se enseña ni se adquiere, sino que se aprehende" (Luengo, 1996, p. 15) y esa aprehensión implica adquisición, conocimiento, análisis, reflexión, apropiación y uso crítico del contenido del texto literario. Esta concepción encaja perfectamente en el enfoque basado en competencias que ha asumido la Universidad Nacional del Altiplano; buscando el desarrollo integral del estudiante. Además, esta información se enmarca en la idea de Martín y Rascón (2015), quienes afirman que la educación literaria "favorece la formación en valores y la formación integral de los futuros maestros" (p. 365). Adicionalmente, con el modelo asumido prioritariamente, se corrobora que para los maestros universitarios la educación literaria ofrece muchas posibilidades para trabajar con temas multiculturales y preparar a los estudiantes para la vida dentro de una sociedad culturalmente heterogénea (Kusá et al, 2014).

El tercer resultado muestra cuáles son las estrategias usadas en la educación literaria que se promueve en la universidad. Estas son diversas, resaltando el comentario de textos, la escritura creativa, la dramatización y la elaboración de ensayos (Tabla 3); estas estrategias se relacionan directamente a los modelos asumidos en el uso de la literatura, siendo la primera una estrategia del modelo textual y las otras tres, del modelo basado en el conocimiento del texto o educación literaria, propiamente dicha. Se debe destacar que para obtener este resultado solo se han considerado a las 27 Escuelas Profesionales que desarrollan componentes curriculares de comprensión y producción de textos.

Tabla 3.

Principales estrategias que promueven la educación literaria.

\begin{tabular}{lc}
\hline Estrategias & \% de uso en las aulas universitarias \\
\hline Comentario de textos & 65 \\
Escritura creativa & 92 \\
Dramatización & 52 \\
Elaboración de ensayos & 100 \\
\hline
\end{tabular}

La estrategia del comentario de textos está mencionada en el $65 \%$ de los sílabos analizados, información que se ha corroborado a través de los cuestionarios aplicados a los estudiantes, indicando estos que hacer un comentario los lleva a leer el texto completo, analizar sus partes y emitir opiniones sobre la forma y el fondo del mismo, opiniones que deben estar debidamente justificadas.

La escritura creativa, que ha surgido como los famosos talleres literarios, es una estrategia que combina la intertextualidad y la imaginación para poder producir textos de manera lúdica, es 
usada por el $92 \%$ de los docentes que fomentan una educación literaria en las aulas universitarias. Al respecto, los estudiantes afirman sentirse muy cómodos con esta estrategia, ya que les proporciona libertad para crear. Esto se relaciona a la idea de concebir la escritura creativa como "una tradición lúdica e intelectual que se convierte en un paradigma didáctico que encuentra su principal soporte en el fomento de los procesos lectores y en el desarrollo de la competencia literaria" (Dueñas, 2013, p. 144).

La dramatización es una estrategia que está presente en el $52 \%$ de los sílabos analizados, se utiliza para la compresión de textos como para la producción oral y escrita. Esta estrategia les da a los estudiantes la oportunidad de desarrollar su aspecto cognitivo, emocional, social y mucho más; puesto que como afirma González (2015) "mediante la dramatización ayudamos a los estudiantes a construir su propia realidad desde su visión personal, con el fin de llegar a un consenso con el grupo ante una situación presentada" (p. 101). Esta forma de fomentar la educación literaria, según los estudiantes, es útil y divertida; les permite, sobre todo, vencer su timidez y ayudarlos a entender textos y producirlos, según diversos contextos.

La elaboración de ensayos es la estrategia que aparece en el $100 \%$ de los sílabos revisados, lo cual indica que todos los docentes fomentan su producción, considerando que es la mejor práctica para que el estudiante lea y escriba. Ya sea que el docente promueva la redacción de un ensayo literario o de uno académico-científico, lo importante es que se busca que el estudiante desarrolle su pensamiento crítico a través de la presentación de argumentos que den solidez a su postura en relación a diversos temas. Además se considera que el ensayo literario y el académicocientífico se relacionan, pues se conocen ensayos científicos que usan elementos estilísticos del ensayo literario y ensayos literarios que utilizan la rigurosidad científica en su expresión (Zambrano, 2012). Esta estrategia es tomada como un reto para los estudiantes, afirmando ellos que los obliga a leer, entender y proponer nuevas ideas, defendiéndolas con argumentos sólidos, para mostrar su posición.

Haber encontrado que el comentario de textos, la escritura creativa, la dramatización y la elaboración de ensayos son las estrategias más usadas en la educación literaria, explícita e implícita, que se da en las aulas universitarias es un aspecto que coincide con la idea de afirmar que "la educación literaria debe realizarse a través de acciones comunicativas dialógicas: escenificación, lectura y escritura (Vargas, 2009, p. 39), es decir la educación literaria debe usar acciones dinámicas para que el estudiante conozca, sienta y viva la experiencia de comprender y producir textos. Esto respalda la idea de indicar que con la educación literaria "se trata de situar a los jóvenes alumnos en una larga tradición de pensamiento, de hipótesis, de explicaciones o dudas que le puedan amparar en su vida y que les proporcionen parámetros desde los que entender el mundo y entenderse mejor a sí mismos" (Dueñas, 2013, p. 142).

El último resultado de la investigación se refiere al nivel de desarrollo de las capacidades comunicativas de comprensión y producción de textos en los estudiantes universitarios. Estas se encuentran en un nivel medio, que en una escala vigesimal corresponde a un promedio de 12.4 (Tabla 4). Debe destacarse que los estudiantes tienen mejor logro en la capacidad de producción de textos, demostrando que son capaces de emitir diversos mensajes con un propósito concreto; aunque teniendo varias debilidades, sobre todo cohesivas (puntuación y uso de conectores). Estos resultados hacen evidente que se deben incrementar acciones orientadas al desarrollo de la competencia comunicativa, ya que esta es imprescindible para el desenvolvimiento personal y profesional de todos los seres humanos; reconociendo, además, que las habilidades de comprensión y producción de textos son una herramienta fundamental para potenciar las relaciones de la persona con uno mismo, con los otros y con el mundo, pues con toda seguridad, si la comprensión implica entender el mundo, la producción nos lleva a construir uno nuevo y eso es lo que necesitamos en la formación profesional, siendo la educación literaria una maravillosa oportunidad para lograrlo.

Tabla 4.

Nivel de comprensión y producción de textos.

\begin{tabular}{lcc}
\hline \multicolumn{1}{c}{ Capacidad } & \multicolumn{2}{c}{ Nivel } \\
& Cualitativo & Cuantitativo \\
\hline Comprensión de textos & Medio & 11,6 \\
Producción de textos & Medio & 13,2 \\
Promedio & Medio & 12,4 \\
\hline
\end{tabular}

Encontrar que el nivel de comprensión y producción de textos de los estudiantes universitarios es medio, deriva en la necesidad de fortalecer su 
competencia comunicativa, entendiendo que esta no es responsabilidad íntegra de cada estudiante, pues se debe reconocer que en su desarrollo influyen varios aspectos: docente, familia, estrategias, sociedad y otros; lo cual concuerda con la idea de concebir que:

Las dificultades en la comunicación no son un problema personal, un problema que señala las carencias de un sujeto al que hay que proveer de recursos para fortalecer el desarrollo de sus habilidades comunicativas; por el contrario, estas hacen referencia a un problema que se genera y se construye en contextos sociales e institucionales, como la familia o la escuela (Marín, 2014, p. 61).

Así mismo, este resultado se enmarca en la idea de Dueñas (2013) quien afirma que:

Al sistema educativo le corresponde desarrollar ámbitos propicios, susceptibles de provocar la afición a la lectura en los alumnos, aunque no surta los efectos deseados en todos ellos, porque la decisión de leer al margen ya de un marco obligatorio depende de la trayectoria personal, de la estimulación familiar, de las expectativas sociales que se interioricen, de los entornos afectivos en que se desenvuelve un individuo, etc. (p. 142).

\section{Conclusiones}

La educación literaria está presente en el $77 \%$ de las Escuelas Profesionales de la Universidad Nacional del Altiplano, ya sea explícita o implícitamente, a través del desarrollo de los componentes curriculares de comprensión y producción de textos.

Coexisten dos modelos en el uso de la literatura: el modelo textual y el modelo basado en el conocimiento del texto, que corresponde a la educación literaria. Este último es el que más se usa y se orienta a desarrollar procesos de comprensión y producción literaria en, desde y para la vida, construyendo un pensamiento crítico y creativo. Se destaca, también, que la educación literaria se enmarca en el enfoque basado en competencias, asumido por la Universidad.

Las estrategias más usadas en la educación literaria en las aulas universitarias son: el comentario de textos, la escritura creativa, la dramatización y la producción de ensayos; todas ellas orientadas a desarrollar procesos de comprensión y producción de textos orales y escritos de manera entretenida y eficaz.

El nivel de desarrollo de capacidades de comprensión y producción de textos en los estudiantes universitarios es medio, evidenciando la necesidad de fortalecer la competencia comunicativa a través de diversas acciones, siendo una de ellas la implantación de una educación literaria en toda la Universidad, quedando muchos aspectos por investigar en relación a este tema.

\section{Referencias bibliográficas}

Aguiar, E. (1980). Competencia lingüistica y competencia literaria. Madrid: Gredos.

Baños, J. (2003). El valor de la literatura en la formación de los estudiantes de medicina. Educación Médica, 6(2), 3743. Disponible en: http://scielo.isciii.es/ scielo.php? script $=$ sci arttext\&pid $=\mathrm{S} 1575$ $18132003000200005 \& \operatorname{lng}=\mathrm{es}$.

Barrales, A., Villalobos, M., Landín, M., Pérez, M., Cruz, I. y Rodríguez, A. (2012). El enfoque educativo basado en competencias. Educación, XXI (41), 23-39.

Blázquez, A. y Martínez-Lozano, V. (2012). La Residencia Universitaria Flora Tristán: un Ejemplo de Formación Humana y de Compromiso con la Sociedad. Revista de Educación (358), 618-630. doi: 104438/1988-592X-RE-2011-358-145

Clavijo, D. (2015). El enfoque de competencias en la formación del abogado para el siglo XXI. Justicia (27), 185-212.

Colomer, T. (2002). ¿Qué significa progresar en competencia literaria?. Textos en Contexto. La literatura en la escuela.5, 12-25.

Colomer, T. (2010). La didáctica de la literatura: temas y líneas de investigación e innovación. Disponible en: http://www.cervantesvirtual. com/nd/ark:/59851/bmcpv725. Accedido el 13 de junio de 2018.

Delors, J. (1996). La educación encierra un tesoro. Informe a la Unesco de la Comisión Internacional sobre la educación para el Siglo XXI. Madrid: Santillana: Unesco.

Díaz, A. (2006). El enfoque de competencias en la educación. ¿Una alternativa o un disfraz de cambio? Perfiles educativos, 28(111), 7-36. Disponible en: http://www.scielo.org.mx/ scielo.php? script $=$ sci $\operatorname{arttext\& pid=S0185-}$ 
26982006000100002\&lng=es\&tlng=es

Dueñas, J. (2013). La educación literaria. Revisión teórica y perspectivas de futuro. Didáctica. Lengua y Literatura, 25, 135-156.

González, J. (2015). Dramatización y educación emocional. Revista de Investigación Educativa 21, 98-119. Disponible en: http://revistas. uv.mx/index.php/cpue/article/view/1723

Hernández, R., Fernández, C., \& y Baptista, P. (2014). Metodología de la Investigación. $6^{\circ}$ edición. México: McGRAW-HILL.

Hoevel, C. (2015). Ante la llegada de la business university. Revista Integra Educativa, 8(2), 44-62. Disponible en: https://goo.gl/cZfrjS

Ibarra, N. y Ballester, J. (2016). La literatura en la formación universitaria desde el espacio europeo de educación superior. ALPHA. (43), 303-317.

Kusá, J., Sladová, J. y Kopecký, K. (2014). Literary Education as a Place for Multicultural Dialogue. Procedia - Social and Behavioral Sciences, 149, 479 - 483. doi: 10.1016/j. sbspro.2014.08.294

Kusá, J., Sladová, J., Kopecký, K., \& Mlčoch, M. (2014). Multicultural literary education and its didactic aspects. Procedia - Social and Behavioral Sciences, 112, 300 - 308. doi: 10.1016/j.sbspro.2014.01.1168

Lázaro, F., \& Correa, E. (1970). Cómo se comenta un texto literario. Salamanca: Anaya.

Licandro, O. y Yepes, S. (2018). La Educación Superior conceptualizada como Bien Común: El desafío propuesto por UNESCO. Revista Digital de Investigación en Docencia Universitaria, 12(1), 6-33. doi:10.19083/rid

Luengo, J. (1996). Educación literaria y realidad en las aulas. Córdoba: Universidad de Córdoba.

Marín, G. (2014). Habilidades comunicativas en estudiantes universitarios: Viejas problemáticas y nuevos retos. Docencia Universitaria, 15, 49- 67.

Martín, M. y Rascón, D. (2015). La educación literaria: una oportunidad de aprendizaje servicio para la formación integral del futuro maestro. Profesorado, 19(1), 350-366.
Martínez, H. (2009). El enfoque basado en competencias en la educación universitaria. Disponible en: http://www.perueduca.pe/ documents/172628/0/E1\%20enfoque $\% 20$ basado $\% 20$ en $\% 20$ competencias.pdf. Accedido el 12 de agosto de 2018.

Mata, J. y Villarrubia, A. (2011). La literatura en las aulas. Apuntes sobre la educación literaria en la enseñanza secundaria. Textos de Didáctica de la Lengua y la Literatura, (58), 49-59.

Morote, E. (2014). La escritura creativa en las aulas del grado de primaria. Una investigación Acción. Universidad de Murcia. Tonos digital: Revista de estudios filológicos (26). Disponible en: https://digitum.um.es/ digitum/bitstream/10201/39169/1/La\%20 escritura $\% 20$ creativa $\% 20$ en $\% 201 \mathrm{as} \% 20$ aulas.pdf

Prado, J. (2004). Didáctica de la lengua y la literatura para educar en el siglo XXI. Madrid: La Muralla.

Universidad Nacional del Altiplano. (2013). Proyecto Educativo Universitario. Puno Perú: Editorial El Altiplano.

Rabuzzi, K. (1982). Literature and Medicine: Toward a New Discipline. Nueva York: State Univ of New York Pr.

Tejerina, I. (1994). Dramatización y teatro infantil. Dimensiones psicopedagógicas y expresivas. Madrid: Siglo XXI.

Tiza, M., Campos, E., \& Castellón, Y. (2016). La formación de la competencia literaria: un reto para la educación de estos tiempos. Invest. pens. crit., 4(2), 115-125.

Tobón, S. (2010). Secuencias didácticas: aprendizaje y evaluación de competencias. México: Pearson Education.

Vargas, P. (2009). La educación literaria a través del dialogismo. Enunciación, 14(2), 33-41.

Zambrano, J. (2012). El ensayo: concepto, características, composición. Sophia (8). Disponible en: http://www.redalyc. org/articulo.oa?id=4137/413740749012. Accedido el 30 de mayo de 2019. 